\title{
Social Solidarity and the Enforcement of Morality
}

\author{
H. L. A. Hart
}

It is possible to extract from Plato's Republic and Laws, and perhaps from Aristotle's Ethics and Politics, the following thesis about the role of law in relation to the enforcement of morality: the law of the city state exists not merely to secure that men have the opportunity to lead a morally good life, but to see that they do. According to this thesis not only may the law be used to punish men for doing what morally it is wrong for them to do, but it should be so used; for the promotion of moral virtue by these means and by others is one of the Ends or Purposes of a society complex enough to have developed a legal system. This theory is strongly associated with a specific conception of morality as a uniquely true or correct set of principles-not manmade, but either awaiting man's discovery by the use of his reason or (in a theological setting) awaiting its disclosure by revelation. I shall call this theory "the classical thesis" and not discuss it further.

From the classical thesis there is to be distinguished what $I$ shall call "the disintegration thesis." This inverts the order of instrumentality between society on the one hand and morality on the other as it appears in the classical thesis; for in this thesis society is not the instrument of the moral life; rather morality is valued as the cement of society, the bond, or one of the bonds, without which men would not cohere in society. This thesis is associated strongly with a relativist conception of morality: according to it, morality may vary from society to society, and to merit enforcement by the criminal law, morality need have no rational or other specific content. It is not the quality of the morality but its cohesive power which matters. "What is important is not the quality of the creed but the strength of the belief in it. The enemy of society is not error but indifference." 1 The case for the enforcement of morality on this view is that its maintenance is necessary to prevent the disintegration of society.

H. L. A. Hart is Professor of Jurisprudence at Oxford University and Fellow of University College, Oxford.

1 P. Devin, The Enforcement of Morats 114 (1965) [hereinafter cited as Devlin]. Cf. id. at 94: "Unfortunately bad societies can live on bad morals just as well as good societies on good ones." 
The disintegration thesis, under pressure of the request for empirical evidence to substantiate the claim that the maintenance of morality is in fact necessary for the existence of society, often collapses into another thesis which I shall call "the conservative thesis." This is the claim that society has a right to enforce its morality by law because the majority have the right to follow their own moral convictions that their moral environment is a thing of value to be defended from change. ${ }^{2}$

The topic of this article is the disintegration thesis, but I shall discharge in relation to it only a very limited set of tasks. What I shall mainly do is attempt to discover what, when the ambiguities are stripped away, is the empirical claim which the thesis makes and in what directions is it conceivable that a search for evidence to substantiate this claim would be rewarding. But even these tasks I shall discharge only partially.

\section{I}

The disintegration thesis is a central part of the case presented by Lord Devlin ${ }^{3}$ justifying the legal enforcement of morality at points where followers of John Stuart Mill and other latter day liberals would consider this an unjustifiable extension of the scope of the criminal law. The morality, the enforcement of which is justified according to Lord Devlin, is variously described as "the moral structure" of society, "a public morality," "a common morality," "shared ideas on politics, morals, and ethics," "fundamental agreement about good and evil," and "a recognised morality." This is said to be part of "the invisible bonds of common thought" which hold society together; and "if the bonds were too far relaxed the members would drift apart." $\mathrm{It}$ is part of "the bondage ... of society" and is "as necessary to society as, say, a recognised government." 8 The justification for the enforcement of this recognised morality is simply that the law may be used to preserve

2 This characterization of the conservative thesis is taken from Dworkin, Lord Devlin and the Enforcement of Morals, 75 Yale L.]. 986 (1966). Professor Dworkin distinguishes the parts played in Lord Devlin's work by the disintegration thesis and the conservative thesis, and his essay is mainly concerned with the critical examination of Lord Devlin's version of the latter. The present essay, by contrast, is mainly concerned to determine what sort of evidence is required if the disintegration thesis is not to collapse into or to be abandoned for the conservative thesis.

3 See principally the lecture by Lord Devlin entitled "The Enforcement of Morals" which he delivered as the Second Maccabaean Lecture in Jurisprudence of the British Academy and which is reproduced in Devus ch. I as "Morals and the Criminal Law."

4 Devirn 9-11.

5 Devirin 10.

6 Devita 10-11. 
anything essential to society's existence. "There is disintegration when no common morality is observed and history shows that the loosening of moral bonds is often the first stage of disintegration."7 If we consider these formulations they seem to constitute a highly ambitious empirical generalisation about a necessary condition for the existence or continued existence of a society and so give us a sufficient condition for the disintegration of society. Apart from the one general statement that "history shows that the loosening of moral bonds is often the first stage of disintegration," no evidence is given in support of the argument and no indication is given of the kind of evidence that would support it, nor is any sensitivity betrayed to the need for evidence.

In disputing with Lord Devlin, ${ }^{8} \mathrm{I}$ offered him the alternative of supplementing his contentions with evidence, or accepting that his statements about the necessity of a common morality for the existence of society were not empirical statements at all but were disguised tautologies or necessary truths depending entirely on the meaning given to the expressions "society," "existence," or "continued existence" of society. If the continued existence of a society meant living according to some specific shared moral code, then the preservation of a moral code is logically and not causally or contingently necessary to the continued existence of society and this seems too unexciting a theme to be worth ventilating. Yet at points Lord Devlin adopts a definition of society ("a society means a community of ideas"') which seems to suggest that he intended his statements about the necessity of a morality to society's existence as a definitional truth. Of course, very often the expressions "society," "existence of society," and "the same society" are used in this way: that is, they refer to a form or type of social life individuated by a certain morality or moral code or by distinctive legal, political, or economic institutions. A society in the sense of a form or type of social life can change, disappear, or be succeeded by different forms of society without any phenomenon describable as "disintegration" or "members drifting apart." In this sense of "society," post-feudal England was a different society from feudal England. But if we express this simple fact by saying that the same English society was at one time a feudal society and at another time not, we make use of another sense of society with different criteria of individuation and continued identity. It is plain that if the threat of disintegration or "members drifting apart" is to have any reality, or if the claim that a

7 DEVLIN 13.

8 See H.L.A. Hart, LAw, Liberty and Morality (1963).

8 Devur 10 (emphasis added). But cf. id. at 9: "What makes a society of any sort is community of ideas ...." 
common morality is "as necessary to society as, say, a recognised government" is taken to be part of an argument for the enforcement of morality, definitional truths dependent upon the identification of society with its shared morality are quite irrelevant. Just as it would be no reply to an anarchist who wished to preserve society to tell him that government is necessary to an organised society, if it turned out that by "organised society" we merely meant a society with a government, so it is empty to argue against one who considers that the preservation of society's code of morality is not the law's business, that the maintenance of the moral code is necessary to the existence of society, if it turns out that by society is meant a society living according to this moral code.

The short point is that if we mean by "society ceasing to exist" not "disintegration" nor "the drifting apart" of its members but a radical change in its common morality, then the case for using the law to preserve morality must rest not on any disintegration thesis but on some variant of the claim that when groups of men have developed a common form of life rich enough to include a common morality, this is something which ought to be preserved. One very obvious form of this claim is the conservative thesis that the majority have a right in these circumstances to defend their existing moral environment from change. But this is no longer an empirical claim.

\section{II}

Views not dissimilar from Lord Devlin's, and in some cases hovering in a similar way between the disintegration thesis and the conservative thesis, can be found in much contemporary sociological theory of the structural and functional prerequisites of society. It would, for example, be profitable, indeed necessary for a full appreciation of Talcott Parson's work, to take formulations of what is apparently the disintegration thesis which can be found in almost every chapter of his book The Social System, and enquire (i) what precisely they amount to; (ii) whether they are put forward as empirical claims; and (iii) if so, by what evidence they are or could be supported. Consider, for example, such formulations as the following: "The sharing of such common value patterns .... creates a solidarity among those mutually oriented to the common values .... [W]ithout attachment to the constitutive common values the collectivity tends to dissolve." 10 "This integration of a set of common value patterns with the internalized need-disposition structure of the constituent personalities is the core phenomenon

10 T. Parsons, The Social. System 41 (1951). 
of the dynamics of social systems. That the stability of any social system is dependent on a degree of such integration may be said to be the fundamental dynamic theorem of sociology."11 The determination of the precise status and the role of these propositions in Parson's complex works would be a task of some magnitude, so I shall select from the literature of sociology Durkheim's elaboration of a form of the disintegration theory, because his variant of the theory as expounded in his book, The Division of Labour in Society, is relatively clear and briefly expressed, and is also specifically connected with the topic of the enforcement of morality by the criminal law.

Durkheim distinguishes two forms of what he calls "solidarity" or factors tending to unify men or lead them to cohere in discriminable and enduring societies. The minimum meaning attached to society here is that of a group of men which we can distinguish from other similar groups and can recognise as being the same group persisting through a period of time though its constituent members have been replaced during that time by others. One of the forms of solidarity, "mechanical solidarity," springs from men's resemblances and the other, "organic solidarity," from their differences. Mechanical solidarity depends on, or perhaps indeed consists in, sharing of common beliefs about matters of fact and common standards of behaviour among which is a common morality. This blend of common belief and common standards constitutes the "conscience collective," which draws upon all the ambiguities of the French word conscience as between consciousness or knowledge and conscience. The point of the use of this terminology of conscience is largely that the beliefs and subscription to the common standards become internalised as part of the personality or character of the members of society.

Organic solidarity by contrast depends on the dissimilarities of human beings and their mutual need to be complemented by association in various forms with others who are unlike themselves. The most prominent aspect of this interdependence of dissimilars is the division of labour, but Durkheim warns us that we must not think of the importance of this as a unifying element of society as residing simply in its economic payoff. "[T] he economic services that it [the division of labour] can render are picayune compared to the moral effect that it produces, and its true function is to create in two or more persons a feeling of solidarity."12 Generally, mechanical solidarity is the dominant form of solidarity in simple societies and diminishes in importance, though apparently it is never eliminated altogether as a unifying

11 Id. at 42 .

12 E. Durkheim, The Division of Labour in Society 56 (3d ed. Simpson transl. 1964). 
factor, as organic solidarity develops in more complex societies. According to Durkheim the law presents a faithful mirror of both forms of solidarity, and can be used as a gauge of the relative importance at any time of the two forms. The criminal law, with its repressive sanctions, reflects mechanical solidarity; the civil law reflects organic solidarity, since it upholds the typical instruments of interdependence, e.g., the institution of contract, and generally provides not for repressive sanctions, but for restitution and compensation.

Somewhat fantastically Durkheim thinks that the law can be used as a measuring instrument. We have merely to count the number of rules which at any time constitute the criminal law and the number of rules which constitute the civil law expressing the division of labour, and then we know what fraction to assign to the relative importance of the two forms of solidarity. ${ }^{13}$ This fantasy opens formidable problems concerning the individuation and countability of legal rules which occupied Bentham a good deal ${ }^{14}$ but perhaps need not detain us here. What is of great interest, however, is Durkheim's view of the role of the criminal law in relation to a shared morality. Durkheim is much concerned to show the hollowness of rationalistic and utilitarian accounts of the institution of criminal punishment. For him, as for his English judicial counterpart, utilitarian theory fails as an explanatory theory for it distorts the character of crime and punishment and considered as a normative theory would lead to disturbing results. Durkheim therefore provides fresh definitions of both crime and punishment. For him a crime is essentially (though in developed societies there are secondary senses of crime to which this definition does not apply directly) a serious offense against the collective conscience-the common morality which holds men together at points where its sentiments are both strong and precise. Such an act is not condemned by that morality because it is independently a crime or wrong, it is a crime or wrong because it is so condemned. Above all, to be wrong or a crime an act need not be, nor even be believed to be, harmful to anyone or to society in any sense other than that it runs counter to the common morality at points where its sentiments are strong and precise. These features of Durkheim's theory are striking analogues of Lord Devlin's observation that it is not the quality of the morality that matters but the strength of the belief in it and its consequent cohesive power and his stipulation that the morality to be enforced must be

18 Id. at 68.

14 Bentham devoted a whole book to the questions: What is one law? What is part of a law? What is a complete law? see J. BenthaM, The LrMtrs of JURIsprudence Defrned (C. Everett ed. 1945). 
up to what may be called concert pitch: it must be marked by "intolerance, indignation, and disgust." 15

What, then, on this view, is punishment? Why punish? And how severely? Punishment for Durkheim is essentially the hostility excited by violations of the common morality which may be either diffused throughout society or administered by official action when it will usually have the form of specifically graduated measures. His definition, therefore, is that punishment is "a passionate reaction of graduated intensity" to offences against the collective conscience. ${ }^{18}$ The hollowness of utilitarian theory as an explanation of criminal punishment is evident if we look at the way that, even in contemporary society, criminal punishments are graduated. They are adapted not to the utilitarian aim of preventing what would be ordinarily described as harmful conduct, but to the appropriate expression of the degree of feeling excited by the offence, on the footing that such appropriate expression of feeling is a means of sustaining the belief in the collective morality. ${ }^{17}$ Many legal phenomena bear this out. We punish a robber, even if he is likely to offend again, less severely than a murderer whom we have every reason to think will not offend again. We adopt the principle that ignorance of the law is no excuse in criminal matters and, he might have added, we punish attempts less severely than completed offences thereby reflecting a difference in the resentment generated for the completed as compared with the uncompleted crime.

Hence, to the question "Why punish?" Durkheim's answer is that we do so primarily as a symbolic expression of the outraged common morality the maintenance of which is the condition of cohesion resulting from men's likenesses. Punishing the offender is required to maintain social cohesion because the common conscience, violated by the offence, "would necessarily lose its energy if an emotional reaction of the community [in the form of punishment] did not come to compensate its loss, and it would result in a breakdown of social solidarity." 18

This thumbnail sketch of Durkheim's theory presents its essentials, but there are two complexities of importance, as there are also in Lord Devlin's case. Both have to do with the possibilities of change in the common morality. Both theorists seem to envisage a spontaneous or natural change and warn us in different ways that the enforcement of morality must allow for this. Thus Lord Devlin issues prudential

15 DevulN viii-ix, 17 .

16 E. Durrheim, The Division of Labour in Society 90 (3d ed. Simpson transl. 1964).

17 Cf. DevLIN 114: "When considering intangible injury to society it is moral belief that matters; immoral activity is relevant only insofar as it promotes disbelief."

18 E. Durkhem, The Division of Labour in Society 108 (3d ed. Simpson transl. 1964). 
warnings to the legislator that "[t]he limits of tolerance shift"18 and that we should not make criminal offences out of moral opinion which is likely soon to change and leave the law high, and, so to speak, morally dry. Durkheim similarly says that his theory does not mean that it is necessary to conserve a penal rule because it once corresponded to the collective sentiments, but only if the sentiment is still "living and energetic." If it has disappeared or enfeebled, nothing is worse than trying to keep it alive artificially by the law. ${ }^{20}$ This means that we must distinguish a natural or nonmalignant change in the social morality or a natural "shift in its limits of tolerance" from a malignant form of change against which society is to be protected and which is the result of individual deviation from its morality. It is, however, a further complexity in these theories that the function of punishment, or rather the mechanism by which punishment operates in preserving a social morality from malignant change, differs as between Durkheim and Lord Devlin. For Lord Devlin punishment protects the existing morality by repressing or diminishing the number of immoral actions which in themselves are considered "to threaten" or weaken the common morality. For Durkheim, however, punishment sustains the common morality, not mainly by repressing the immoral conduct, but principally by giving satisfactory vent to a sense of outrage because if the vent were closed the common conscience would "lose its energy" and the cohesive morality would weaken.

\section{III}

If we ask in relation to theories such as Lord Devlin's and Durkheim's precisely what empirical claim they make concerning the connection between the maintenance of a common morality and the existence of society, some further disentangling of knots has to be done.

It seems a very natural objection to such theories that if they are to be taken seriously as variants of the disintegration thesis, the justification which they attempt to give for the enforcement of social morality is far too general. It is surely both possible and good sense to discriminate between those parts of a society's moral code (assuming it has a single moral code) which are essential for the existence of a society and those which are not. Prima facie, at least, the need for such a discrimination seems obvious even if we assume that the moral code

10 DEvLIN 18. Cf. id. at 114: "[T] change of an old morality for a new one ... [ [1]t is the interregnum of disbelief that is perilous."

20 E. Durkheim, The Division of Labour in SOciety 107 n.45 (3d ed. Simpson transl. 1964). 
is only to be enforced where it is supported by "sentiments which are strong and precise" (Durkheim) or by "intolerance, indignation and disgust" (Devlin). For the decay of all moral restraint or the free use of violence or deception would not only cause individual harm but would jeopardise the existence of a society since it would remove the main conditions which make it possible and worthwhile for men to live together in close proximity to each other. On the other hand the decay of moral restraint on, say, extramarital intercourse, or a general change of sexual morality in a permissive direction seems to be quite another matter and not obviously to entail any such consequences as "disintegration" or "men drifting apart."21

It seems, therefore, worthwhile pausing to consider two possible ways of discriminating within a social morality the parts which are to be considered essential.

(i) The first possibility is that the common morality which is essential to society, and which is to be preserved by legal enforcement, is that part of its social morality which contains only those restraints and prohibitions that are essential to the existence of any society of human beings whatever. Hobbes and Hume have supplied us with general characterisations of this moral minimum essential for social life: they include rules restraining the free use of violence and minimal forms of rules regarding honesty, promise keeping, fair dealing, and prop-

21 Lord Devlin in a footnote concedes that not every breach of a society's moral code threatens its existence. His words are: "I do not assert that any deviation from a society's shared morality threatens its existence any more than $I$ assert that any subversive activity threatens its existence. I assert that they are both activities which are capable in their nature of threatening the existence of society so that neither can be put beyond the law." Devur 13 n.1. (emphasis in original). This passage does not mean or imply that there are any parts of a social morality which though supported by indignation, intolerance, and disgust can be regarded as not essential for society's existence: on this point Lord Devlin plainly inclines towards the conception of a social morality as a seamless web. Devirn 115. But Professor Dworkin argues, convincingly in my opinion, that Lord Devlin uses the same criterion (in effect "passionate public disapproval") to determine both that a deviation from public morality may conceivably threaten its existence and that it in fact does so, so as to justify actual punishment. Dworkin, Lord Devlin and the Enforcement of Morals, 75 YALE L.J. 986, 990-92 (1966). This leaves his version of the disintegration thesis without empirical support. Thus, according to Lord Devlin: "We should ask ourselves in the first instance whether, looking at homosexuality calmly and dispassionately, we regard it as a vice so abominable that its mere presence is an offense. If that is the genuine feeling of the society in which we live, I do not see how society can be denied the right to eradicate it." DEvLnN 17 . But he offers no evidence that in these circumstances the legal toleration of homosexuality would in fact endanger society's existence. Contrast the foregoing with the principles applied by Lord Devlin to fornication in relation to which "feeling may not be so intense." In that case: "It becomes then a question of balance, the danger to society in one scale and the extent of the restriction in the other." DeviIN 17-18 (emphasis added). 
exty. It is, however, quite clear that neither Devlin nor Durkheim means that only these elements, which are to be found in common morality, are to be enforced by law, since any utilitarian or supporter of the Wolfenden Report would agree to that. Quite clearly the argument of both Lord Devlin and Durkheim concerns moral rules which may differ from society to society. Durkheim actually insists that the common morality, violations of which are to be punished by the criminal law, may have no relation to utility: "It was not at all useful for them [these prohibitions] to be born, but once they have endured, it becomes necessary that they persist in spite of their irrationality." 22 The morality to be punished includes much that relates "neither to vital interests of society nor to a minimum of justice."23

(ii) The second possibility is this: the morality to be enforced, while not coextensive with every jot and tittle of an existent moral code, includes not only the restraints and prohibitions such as those relating to the use of violence or deception which are necessary to any society whatever, but also what is essential for a particular society. The guiding thought here is that for any society there is to be found, among the provisions of its code of morality, a central core of rules or principles which constitutes its pervasive and distinctive style of life. Lord Devlin frequently speaks in this way of what he calls monogamy adopted "as a moral principle," 24 and of course this does deeply pervade our society in two principal ways. First, marriage is a legal institution and the recognition of monogamy as the sole legal form of marriage carries implications for the law related to wide areas of conduct: the custody and education of children, the rules relating to inheritance and distribution of property, etc. Second, the principle of monogamy is also morally pervasive: monogamous marriage is at the heart of our conception of family life, and with the aid of the law has become part of the structure of society. Its disappearance would carry with it vast changes throughout society so that without exaggeration we might say that it had changed its character.

On this view the morality which is necessary to the existence of society is neither the moral minimum required in all societies (Lord Devlin himself says that the polygamous marriage in a polygamous society may be an equally cohesive force as monogamy is in ours), ${ }^{25}$ nor is it every jot and tittle of a society's moral code. What is essential and is to be preserved is the central core. On this footing it would be

22 E. Durkheim, The Division of Labour in Society 107 (3d ed. Simpson transl. 1964). 
an open and empirical question whether any particular moral rule or veto, e.g., on homosexuality, adultery, or fornication, is so organically connected with the central core that its maintenance and preservation is required as a vital outwork or bastion. There are perhaps traces of some of these ideas in Lord Devlin but not in Durkheim. But even if we take this to be the position, we are still not really confronted with an empirical claim concerning the connection of the maintenance of a common morality and the prevention of disintegration or "drifting apart." Apart from the point about whether a particular rule is a vital outwork or bastion of the central core, we may still be confronted only with the unexciting tautology depending now on the identification of society, not with the whole of its morality but only with its central core or "character" and this is not the disintegration thesis.

\section{IV}

What is required to convert the last mentioned position into the disintegration thesis? It must be the theory that the maintenance of the core elements in a particular society's moral life is in fact necessary to prevent disintegration, because the withering or malignant decay of the central morality is a disintegrating factor. But even if we have got thus far in identifying an empirical claim, there would of course be very many questions to be settled before anything empirically testable could be formulated. What are the criteria in a complex society for determining the existence of a single recognised morality or its central core? What is "disintegration" and "drifting apart" under modern conditions? I shall not investigate these difficulties but I shall attempt to describe in outline the types of evidence that might conceivably be relevant to the issue if and when these difficulties are settled. They seem to be the following:

(a) Crude historical evidence in which societies - not individualsare the units. The suggestion is that we should examine societies which have disintegrated and enquire whether their disintegration was preceded by a malignant change in their common morality. This done, we should then have to address ourselves to the possibility of a causal connection between decay of a common morality and disintegration. But of course all the familiar difficulties involved in macroscopic generalisations about society would meet us at this point, and anyone who has attempted to extract generalisations from what is called the decline and fall of the Roman Empire would know that they are formidable. To take only one such difficulty: suppose that all our evidence was drawn from simple tribal societies or closely knit agrarian societies 
(which would seem to be the most favourable application of Durkheim's theory of mechanical solidarity). We should not, I take it, have much confidence in applying any conclusions drawn from these to modern industrial societies. Or, if we had, it would be because we had some well developed and well evidenced theory to show us that the differences between simple societies and our own were irrelevant to these issues as the differences in the size of a laboratory can safely be ignored as irrelevant to the scope of the generalisations tested by laboratory experiments. Durkheim, it may be said, is peculiarly obscure on just this point, since it is not really clear from his book whether he means that in advanced societies characterized by extensive division of labour the mechanical solidarity which would still be reflected in its criminal law could be disregarded or not.

(b) The alternative type of evidence must be drawn presumably from social psychology and must break down into at least two subforms according to the way in which we conceive the alternatives to the maintenance of a common morality. One alternative is general uniform permissiveness in the area of conduct previously covered by the common morality. The lapse, for example, of the conception that the choices between two wives or one, heterosexuality or homosexuality, are more than matters of personal taste. This (the alternative of permissiveness) is what Lord Devlin seems to envisage or to fear when he says: "The enemy of society is not error but indifference," and "Whether the new belief is better or worse than the old, it is the interregnum of disbelief that is perilous." ${ }^{28}$ On the other hand the alternative may be not permissiveness but moral pluralism involving divergent submoralities in relation to the same area of conduct.

To get off the ground with the investigation of the questions that either of these two alternatives opens up, it would be reasonable to abandon any general criteria for the disintegration of society in favour of something sufficiently close to satisfy the general spirit of the disintegration thesis. It would be no doubt sufficient if our evidence were to show that malignant change in a common morality led to a general increase in such forms of antisocial behaviour as would infringe what seem the minimum essentials: the prohibitions and restraints of violence, disrespect for property, and dishonesty. We should then require some account of the conceivable psychological mechanisms supposed to connect the malignant decay of a social morality with the increase in such forms of behaviour. Here there would no doubt be signal differences between the alternatives of permissiveness and moral plu- 
ralism. On the permissiveness alternative, the theory to be tested would presumably be that in the "interregnum conditions," without the discipline involved in the submission of one area of life, e.g., the sexual, to the requirements of a common morality, there would necessarily be a weakening of the general capacity of individuals for self control. So, with permissiveness in the area formally covered by restrictive sexual morality, there would come increases in violence and dishonesty and a general lapse of those restraints which are essential for any form of social life. This is the view that the morality of the individual constitutes a seamless web. There is a hint that this, in the last resort, is Lord Devlin's view of the way in which the "interregnum" constitutes a danger to the existence of society: for he replied to my charge that he had assumed without evidence that morality was a seamless web by saying that though "[s]eamlessness presses the simile rather hard," "most men take their morality as a whole."27 But surely this assumption cannot be regarded as obviously true. The contrary view seems at least equally plausible: permissiveness in certain areas of life (even if it has come about through the disregard of a previously firmly established social morality) might make it easier for men to submit to restraints on violence which are essential for social life.

If we conceive the successor to the "common morality" to be not permissiveness but moral pluralism in some area of conduct once covered by a sexual morality which has decayed through the flouting of its restrictions, the thesis to be tested would presumably be that where moral pluralism develops in this way quarrels over the differences generated by divergent moralities must eventually destroy the minimal forms of restraints necessary for social cohesion. The counterthesis would be that plural moralities in the conditions of modern large scale societies might perfectly well be mutually tolerant. To many indeed it might seem that the counter-thesis is the more cogent of the two, and that over wide areas of modern life, sometimes hiding behind lip service to an older common morality, there actually are divergent moralities living in peace.

I have done no more than to sketch in outline the type of evidence required to substantiate the disintegration thesis. Till psychologists and sociologists provide such evidence, supporters of the enforcement of morality would do better to rest their case candidly on the conservative rather than on the disintegration thesis. 